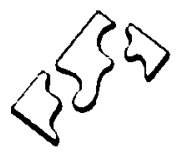

\title{
Living with an Incessantly Crying Infant
}

Roberta J. Hewat

University of British Columbia

It was a beautiful day outside. I had a big table in her bedroom, all the diapers and everything were on it and she was lying there screaming and crying and all I can think about is shaking this child and throwing her against the wall or hitting her. I can understand how people kill their children, how a woman can be so desperate that she will kill that child because it's constantly at you. It never stops. It just never goes away.

I remember picking her up and seeing the wall behind me, this old wall, thinking, I've had it. I'm going to drive her through this wall, so I put her down, put all the pillows around her and went upstairs. ${ }^{1}$

Two mothers of incessantly crying infants illustrate how they almost injured their child. How is this possible? Babies are small, gentle, soft, delicate, and helpless. It seems almost inconceivable how anyone could harm an infant. However, the irritating sound of constant crying and screeching and the inability to alleviate the infant's distress and stop the crying can bring a caretaker to the edge and trigger a catastrophic outcome. It is a delicate balance between maintaining or losing control. Fortunately, parents are usually able to restrain themselves from abusive action. As one mother remarks, "it must be the superior intellect taking over."

Listening to an infant relentlessly crying for hours can be devastating, yet many parents, and particularly mothers, are faced with this anguish for days and nights, and frequently weeks and months. What is this experience like for these parents? What is the significance of living with an incessantly crying infant?

Is there anything that will stop the crying? There is no shortage of advice: "She needs bigger burps." "She's hungry." "You're overfeeding her." "You pick him up too much." "He's overstimulated." "You're nervous." "It must be something you're eating." "Give him gripe water." "Give her bentylol." "Give him a teaspoon of whisky." "Sit her on the dryer and turn it on." "Take him for a car ride." "Massage her with bear grease." "Drink wine before every feeding." The suggestions are endless and parents, in desperation, try everything, just in case something might work. But nothing stops the crying. Strategies that parents use to console most infants during normal fussy periods do not alleviate the distress of some infants. These are called relentless criers or incessant- 
ly crying infants. But why do infants cry? What do we know about the cry?

\section{An Infant's Cry}

An infant's birth cry indicates the culmination of a pregnancy and the beginning of a new life. Although now a fallacy, the longstanding belief that crying is essential for initiating the infant's respiration has many parents listening for their infant's cry at the moment of birth. A lusty cry is regarded as a sign that a healthy, robust infant has been born. The cry announces, "I am here!" And the announcement entices parents to turn their attention to the infant. Parents react and respond. When the first cry quickly subsides, they continue observing their infant more calmly. When crying continues, they ask, "why is she crying?" "What is the matter?" Infants who do not cry or elicit weak or unexpected sounds also invoke an anxious response from parents. They ask, "why does he sound like that?" Or, "why doesn't she cry?" "What is wrong?" As parents are drawn to the infant they reach out in concern, to comfort and console, moments after birth. Is a birth cry necessary? What does it mean?

The term cry derives from the Latin word quiritire meaning to cry out for help or, the utterance of the emotion of affection or distress especially when inarticulate (Oxford Dictionary, 1971, p. 547). Is the birth cry an indication of distress? Is the infant signaling for help? Women who have minimal medical interference during labor and who birth their infants in a calm, peaceful environment often witness the arrival of infants who make little sound, who freely unfold their extremities, and who gradually open their eyes. When placed close to the parent, these infants, in a quiet, alert state, gaze into the parent's face initiating eye-to-eye contact and engaging the parent. Is this interaction more pleasurable than the one initiated by an infant's cry? Are infants who cry at birth responding to the distress of the birth experience?

Although parents may cry as a response to the birth experience, their tears of joy, are distinct from the cry of the infant. Unlike adults, infants do not cry in moments of happiness. Tears of joy are a reaction to a tense or long awaited experience, event, or situation that results in a favorable outcome, such as birth of a healthy infant or finding a child that has been missing. For children and adults, crying is also a response to feelings of loss or sadness. However, these reasons that precipitate crying are not in the repertoire of the newborn. The cry of pain, distress, or discomfort is the cry that has greatest similarity between infants and others. Or is this an adult's interpretation? Can we assume that crying as a response to distress is the same for an infant as it is for adults? 
For the infant, crying evokes a total body response. Starting with a whimper it can be noted that muscles tense, the face grimaces, the chin quivers, the eyes narrow, the hands tighten into fists, and the extremities may slightly tremble. As a whimper develops into a cry, tension increases, eyes become tightly closed, breathing becomes more irregular, motor activity escalates, arms and legs flail, and movements become more jerky. In this tense behavioral state the infant draws inward and closes himself or herself off from outside stimuli. Receptivity of interactions with others diminishes. It is only when infants are soothed and reorganize themselves, attaining a calmer state, that they are ready to perceive stimuli in the environment and interact with others.

In contrast to the infant's cry is the infant's smile. The cry "appears to require an effort" while the "smile appears with ease" (Buytendijk, 1988 , p. 21). The cry suppresses reciprocal interactions with others as the infant is encapsulated in the self, whereas the smile generates openness. Energies flow out and beckon a response. The smile is contagious, parents often smile back. The effect is gentling, relaxing, and pleasuring. The smile under discussion is the smile of the infant that occurs between four and six weeks of age. In a phenomenological exploration of the meaning of the first smile of the child, by Buytendijk (1988), this smile is described as a "friendly encounter." It is "an expression ... [and] a response to the person or object toward whom our heart has affectionately opened" (p. 18). In this sense, parents interpret the first smile as the infant's recognition of the parent, saying, "I am glad to see you." This smile is also "the expression of an emerging quality of humanness" (p. 23). The smile is a sign that the infant is developing his or her own individuality and becoming a person within the family group (Rheingold, 1969). As the child develops, smiles for parents become brighter, more exhilarated, and gleeful. At times the child's whole body responds with arms and legs actively moving, stirred with the excitement of seeing the parent. When this occurs, parents are even more delighted and gratified. Interpreted as contentment, pleasure, and appreciation of the care received, the smile is a reward for parents.

Infant crying is also identified in the literature as a reward for parents' caretaking abilities, but in a different way. Crying demands attention and assistance and parents respond by touching, holding, and talking to their infants to soothe and console them. A crying infant who quiets, calms, and molds into the body of the parent who is comforting him or her positively rewards the parent. The change in the infant's behavior is interpreted as "you are parenting and you are doing it right." As parents feel the tension leave the infant's body, they are reassured of their skills in caregiving (Brazelton \& Cramer, 1990). Thus the cry generates feelings of the effectiveness of parenting and provides oppor- 
tunity for positively reinforcing parental behaviors. For most infants, intermittent periods of crying regularly occur in the early months of life. Parents learn to recognize the unique sounds of their infant's cry and to differentiate between several kinds of cries.

Wolff (1969), one of the first investigators, explored the uniqueness of infants' cries and identified four types as pain, hunger, boredom, and discomfort. Boukydis (1979) demonstrated that at three days after birth, mothers can recognize their infants unique cry, and that pain, hunger, and boredom cries can be distinguished by mothers at two weeks and by fathers at three weeks after birth. Can parents identify different cries that readily?

Descriptions of infant crying that may be more familiar to parents are those advanced by Thoman and Browder (1987). They describe four types: the common healthy cry that starts as a whimper but quickly escalates to a "loud, full-throated cry" (p. 144); the distress cry, which is "piercing, unpleasant, and screeching" (p. 144); "the out-of-control cry" that is "full and vigorous" but has "less rhythm and more agitation" (p. 145) than the common healthy cry; and fussing, which is described as a light whimper. All infants can experience these types of crying.

Periods of fussy crying that start at approximately two weeks, peak at six or eight weeks, then gradually diminish are common for many. These daily periods of manageable irritability may last for two or three hours (Brazelton, 1962). Most infants are soothed and calmed by parents who in turn feel competent and proficient as parents. However, what if an infant's response is not what the parent expects? Some infants are not easily calmed and their bodies remain tense even when the crying stops. Some scream, flailing their arms as if angry or frustrated. Others bring their legs to their abdomens as if in pain. Some crying infants arch backward, moving away from instead of toward the parent and this behavior is often interpreted as rejection. Crying periods vary for infants that become known as criers; however, the time between crying episodes is usually short. Some of these infants are labeled by health professionals as irritable or difficult before the mother and infant are discharged from hospital. Others may be two or three weeks old before incessant crying episodes become a frequent pattern. For some it persists for weeks and months. It is these infants who are most disruptive and difficult for parents. This reality of parenting is different from parents' expected realities.

Cocreating, birthing, parenting. A human being enters the world and parents are drawn to their offspring. They look forward to nurturing, loving, protecting, caring, comforting, and providing for all their infant's needs. The experience of parenting is worrying at times, but it also gives pleasure and satisfaction when a crying infant is appeased by feeding, holding, soothing, and quietening during fussy periods. The 
cry of the infant is an appeal that allures and arouses parents. It is a call that demands action. Being able to do for one's own baby. But what if the child cries endlessly, is demanding, and all consuming, and whatever you do does not work? What is it like to try to console the inconsolable?

\section{Will it Ever Stop?}

"It is almost constant crying, I'm lucky if she sleeps an hour out of 24, and that's not a whole hour at a time." "It goes on and on, night becomes day and day becomes night." "It is constant screeching from noon until five or six in the morning. Will it ever stop?"

Living with a child that cries incessantly is an endless endurance. Some infants start crying at birth whereas others are quiet, sleepy, and difficult to awaken until two or three weeks of age, "then all hell breaks loose." One mother relates:

I can tick the day, I remember the day, I can see it still. He was fed and he still cried and cried and cried and then along came the public health nurse for her requisite visit. He was crying and she proceeds to tell me this child's hungry. She said, "he's crying, he's hungry" and I said this child is not hungry, I just fed him, so she picked him up and took my kid and said, "oh, you poor hungry dear" and I just about murdered that woman. He didn't stop all day and that was the beginning and every day after that was exactly the same. He cried and he cried and he cried and he cried and he cried.

The crying may start to decrease when the infant is five or six months old, allowing life for the parents to become bearable; however, crying and irritable behavior continues for 10 or 12 months and sleepless nights persist into the preschool years. "It seems like it is going to be our whole life and you can't imagine that it is going to stop. At first you hope, but when the doctor says it will stop at three months, then six months, and it still doesn't, you begin to think that there is no possibility that it will ever stop." Life with these infants is a timeless duration.

\section{Answering the Cry}

Living with a relentless crier is an experience of constantly, in a sense, answering the infant's call. The crying demands a response. Life becomes a repetitive, daily routine of endless walking with a crying infant positioned either in a Snugli strapped to the front of a parent, or lying face down, extremities dangling, on a parent's forearm. "I can do anything with the baby hanging on my arm, vacuuming, the dishes, making supper. I even go to the bathroom with her there because if I am home alone and put her down the screeching will start all over again and it's horrible." "Walking, walking, walking," "rocking," "standing as I sway back and forth," "dancing, lots of dancing," "car rides, 
especially in the middle of the night," "anything with motion, it goes on and on and on." Yet, there is no time for sleeping, eating, or attending to essential daily activities.

The nighttimes are the longest and mothers generally take this shift. Entire nights can be spent sitting in a rocking chair with a fussing infant on the shoulder or pacing in a basement so the cry will not disturb the household. One mother illustrates:

After walking the floor to calm him, he is quiet at last. I gently lower myself onto a couch, still holding him. I lie down, feeling his weight on my chest and hoping the warmth of my body or my heartbeat will keep him quiet, even for a few minutes. His head is wet with perspiration from the crying. I listen to the sound of the night, it is quiet and still except for his breathing. Short, quick breathes, then a pause, then another longer breath, a sigh, so irregular. I feel some of the tension leaving my body, I am just letting go almost drifting off, then I feel his legs pulling upwards, the tension rising in his body, his head bobs and turns, he starts to move all over and lets out a loud screech. Will the night ever end? Will I ever get some sleep?

Care is continuous. Fortunately, many fathers help by taking their turn and relieving the mothers, each day.

\section{Taking Turns}

Sharing the responsibility of the infant's care is common for many families with crying infants. However, these parents are often separated more than before the infant was born. Little time, if any, is spent together as a family. One parent watches the infant while the other eats and sleeps and when they are together, the infant is there, demanding full attention from one of them. First-time parents wonder, is this what family life is all about?

I have him, crying, all day and then when George comes home at four thirty, he takes him while I make supper. We eat one at a time. He watches him for the evening and I go to bed. At about midnight he comes to bed and says "its your turn," then I'm up, up, up, all night. George often gets up about five [o'clock $\mid$ and I sneak back to bed hoping to get another hour of sleep.

Knowing that the father will take his turn keeps many mothers holding on when they are stretched to the point of breaking. "Even during the night when he is sleeping, I know I can go to him and say, 'okay, this is too much, I can't do it, I just can't do it for one more second,' and he'll get up and take over." Another mother listens each afternoon for her husband's car coming down the driveway, but if he is late, each second is endless. "Five minutes seems like another four hours, I'm crazy, I tell myself, hold on for five minutes. Its like holding on by your fingernails, even one second seems too much, and when he comes in I just throw the baby at him." When waiting for relief, it seems that time can stand still, 
the hands on the clock do not move, and a mother wonders if she will "make it."

Not all husbands are willing to take their turn. One mother relates, "I do it all, it is my duty to get this child to stop crying. Occasionally my husband carries him but not often. I never have a sense that I am getting any help." "Day by day, minute by minute, I don't really know how I do it. It is constant. There is no way out." Having the full responsibility of the crying infant intensifies the experience for the mother.

\section{Getting Away}

Fathers escape to their jobs, and as one mother explains, "I think he can help out at night because he's been away. If we were both here all day I don't know what would happen." Mothers plan specific outings for themselves when fathers are home to provide care. Most try to return home within one or two hours. When help is not readily available mothers have other strategies for getting away. One mother says, "I put him in his crib and let him cry while I take a shower, as long as the water runs I can't hear him." And another explains, "when I can't stand it any longer I go outside, like the other day there was an inch of frost on the picnic table but I sat outside in my nightgown having a cup of tea while he was inside screaming." And a third mother tells her story of how she tried to get away by taking her infant back to the hospital:

I didn't know what to do any more so I said to John, "we have to take her to the hospital, somebody has to help me." We took her and I wouldn't even go into the hospital because I didn't know what to say. I told John to tell them his wife is in the car and that she is not taking this baby home, that they have to do something. So he took Sarah in and came out, I don't know how much later because I was just feeling awful that I had done this thing, sending her to the hospital as if you could send her back. She was sleeping when she came out and as he handed her to me, I asked, "what did they do?" He said, "well, they gave her a suppository," and I said, "oh like what's the good of that?" I was mad. I'm at the end of my rope and I'm begging for help and they give my kid a suppository and send her home. She was supposed to sleep for several hours but by the time we drove home she was awake and crying again.

The mother despairs. She is experiencing a problem without a solution and a limit to professional expertise. Help was not rendered and the crying child was returned to the mother. The imprisonment continued. Desperation for relief yet difficulty in finding it is a dilemma of the reality. Parents eventually realize that they are the only ones that can comfort their infant.

Being There

Crying infants may be even more inconsolable in another's care. The reluctance that new parents often feel about leaving a newborn is 
accentuated when the child is a relentless crier. "He knows who is holding him and if it is not one of us, he screams and fusses even harder." "When friends insist on taking a turn with her, I watch this purple baby crying hysterically, fighting and pulling against them. It's easier to carry her myself." Even in the presence of friends or family who want to help, parents are tied to the crying infant, constantly holding, soothing, walking, and rocking. It is a situation that is demanding and all consuming but also a paradox in that parents feel needed as they are the only ones that can comfort a distressed and vulnerable infant. A mothers relates, "it makes me feel good to know I can be there for her."

Leaving an infant, even with a family member, becomes an impossibility. The first evening out is described by one mother:

We went to the hockey game leaving him with my sister and her husband. We watched the clock all night and didn't enjoy the game. When we got home I heard him crying from the outside. I rushed up the stairs and as I opened the door, I heard my sister say, "oh, thank God they're home." In the living room there was a half eaten pizza, my sister and her husband both looked haggard, and not much was said. My sister pushed Nathan into my arms, they took their coats, and were gone. We've never been out together again because if it is that hard for my sister, I can't trust anyone. He's my baby, if anybody is going to beat him, I'm going to beat him. I can't leave him in any one else's care for the fear of what they would do.

Parents with a crying infant cannot trust anyone with their child for fear of what may happen. They must always be there, there is no relief.

\section{Living in Confinement}

Life is "closing in." "I am closeted." "I am trapped in a nightmare." "My whole life is inside these walls, I don't know what's going on, I don't read the newspaper, I don't know what is on at the movies." Parents, and particularly mothers become enveloped in a narrowed existence. Detached from the world in a life of disruption, always trying but not succeeding in stopping the relentless crying. A father remarks, "when I come in from the outside, I can feel the tension, it is like a madness."

Bollnow (1961) describes the home as an inner space separate from the outer space, "an area of security and peace for man" (p. 34), "an area in which he [or she] can be relieved from continual anxious alertness, into which he [or she] can withdraw in order to return to himself or herself" (p. 33). But for these families the home is not a place of refuge. The crying never ceases and there is no escape, "even when I'm sleeping she enters my dreams. I am totally conscious of her at all times." What effect does this tension have on parents? What effect does it have on the self? 


\section{The Self Cries}

There is no time for oneself, particularly for mothers who are providing constant care. Living becomes mechanistic, the days are one big blur, and everything is dull and grey, like living in a fog. Overwhelmed by concern and responsibility and exhausted from lack of sleep they become immersed in this daily existence and do not realize what is happening to them. "I can get so blamed frustrated I lose it. I can sit on the edge of my bed crying my eyes out for hours at a time because I just don't know what to do." One mother whose child is now older explains: "A crying baby alters your state of consciousness. It is like waking up from an anaesthetic and not really coming back to being yourself. But you don't realize it while you're in it. It's only after you've come out of it that you realize what you've been in." Parents presently living in this existence do not have the insight of hindsight and have difficulty articulating their feelings, whereas parents who have lived with a persistent crier can portray vivid descriptions of their emotional anguish.

There is frustration and feelings of helplessness of not being able to stop the crying, "no matter what you do, nothing works." Frustration sometimes leads to anger, anger directed at the baby for taking so much time, for interfering with sleep, and for provoking worry. These feelings of anger then may generate guilt; from feeling angry at the infant and from feeling inadequate as a parent. Parents ask themselves: "What am I doing wrong?" "Am I to blame for all this crying?" "Am I not a good mom?" "Am I not a good dad?"

Fear for the child is constant, fear that something is medically wrong with the infant. "He screeches and cries but no one can tell me what is wrong." "There has to be something they [doctors] have not found or she wouldn't be crying so much." The worry and concern are unending.

Fear of a caretaker losing control and abusing the child is distressful. Parents do not leave their infant, even with friends or family, for fear of what may happen. Fear of oneself losing control and hurting one's own child is also a possibility. It is common for intense and unwanted feelings or illogical thoughts to occur. "Many times I feel like I'm losing it." Parents question: "What are the boundaries of maintaining or losing control?" "Will I lose control in a moment of irrationality? If I almost lost it once, will I again?" How many crying children are hurt by their parents? It is understandable how it happens. The horror of knowing it is possible to injure your own child is overwhelming. What other effects does a crying infant have on parents?

The Body Cries

"I am so tired from getting up in the night that I hurt." Mothers describe how they feel when lying in bed listening to the crying. "I 
cannot move or get up, my muscles ache, my body burns, my legs feel heavy. Its like a bad flu." A father adds, "The pain and the hurt in sports injuries is nothing, you can live with that. This is a different kind of pain that burns. It hurts more than anything because there is no relief to it." And a mother who frequently sits in a chair all night with her baby on her shoulder, afraid to move, states, "it feels like somebody put a hot poker in your chest because it burns through." The tiredness is inconceivable yet it is difficult to sleep. One mother explains:

I am so tired I cannot fall asleep and I lie there with my eyes closed, I cannot open my eyes, I cannot do a thing but I hear everything that's going on. I hear the cry, it's like an alarm going off, I can hear it and I know I have to get up and I can't and this crying won't stop, like the alarm, going and going and going and going. If I don't get up it won't stop, so I jump out of bed to try and stop the crying.

Mothers become so exhausted they feel weak, nauseated, dizzy, and faint. Several describe how they feel almost numb or as if they are slowly moving in a dream. Many have no interest in eating. Others are frequently told how pale and tired they look. "I know that I look and feel terrible but I've no energy to do anything about it." How does this existence effect relationships with others?

\section{Working Together}

Sharing the responsibility of infant care is propitious for couples during this demanding period. Muddling through together, communicating in writing as they take turns in providing care, crying together when times are particularly tense, and the father recognizing when the mother has a stressful day helps relationships survive. Closer bonds may develop between those who have stable partnerships before the infant is born whereas the relationship is more precarious for others. A mother tells, "we are lucky that we have a very, very strong relationship at this point because if we didn't I probably would run away. At times I could leave the child, or he [husband] could probably leave me."

Respect for each other is fostered between some parents, "John tells me he is impressed with how I am handling this but I don't know what I would do without him. He never loses his temper, gets mad, annoyed, or says 'I have to get out of here."

Holding and comforting each other is the extent of the sexual relationship for many couples. "We're never in bed at the same time, or if we are, we're sleeping or hoping that we'll sleep." As well, mothers in particular, are emotionally and physically depleted. "There is nothing left to give, nothing for anybody. I don't know when we'll ever have any sex life again." 
Are We Abnormal?

Not being like other couples with children is difficult. One mother explains:

We try to do things that normal people do with children but it's hopeless.

Friends take their babies to dinner or the show; we can't even go to a friend's house for coffee because it is too disruptive. He cries so much everyone is upset. I know our friends wonder what is wrong with me, like I can't manage or get organized. It's like I've done something wrong because we have this colicky baby.

These experiences foster feelings of being separate, alone, inadequate, and different. Parents question: Are we really different? Will we ever be like others again? Why us? Is our relationship different with our child?

\section{Interacting with the Child}

The vulnerability of the crying infant draws parents to the child but it also does not let them go. Usual comforting practices do not easily console the infant, rewarding their caregiving and restoring peace and quiet. However, in spite of the frustration and distress parents build a relationship with their child. "I love that little beggar." "How could anyone not love her, she's so helpless." "I feel fortunate I can help him." "At times it is hard but I feel really close to him. We're making it together." "There are good times." One parent relates:

She is very affectionate to us. You think how can somebody who is crying so hard respond, but when you talk to her and hold her she is very responsive, like we bonded, easily, right from the beginning. I can't be mad at her.

Another parent describes how her infant snuggles into her, "his head is under my chin, he is clutching on to me, and he molds into my chest. It feels warm and nice. We spend many hours that way. I don't know if I could stand it if he didn't cuddle." Positive, reciprocal relationships do develop. "It is hard to describe but he tries to smile through his tears, he is trying to be so brave. I smile back even though I may feel like crying myself and tell him how wonderful he is."

The demands on parents are extraordinary in this intense relationship. Many parents wonder how they are surviving and will be able to keep going. So much is given up, time, physical and emotional energy, and relationships with others. The child is "all consuming."

Living with a persistently crying infant has great impact on parents lives, as illustrated by the vivid accounts told by some parents decades later. Through all the parents' descriptions, we try to understand the similarities and differences of each of their experiences and the significance of the experience for each of them. However, Van den Berg 
(1983) reminds us that "every action, every matter, every word has not one, but many meanings" (p. 40). Will we ever know the true meaning of what it is like to live with an incessantly crying infant?

Notes

1. Parents' quotations cited throughout the text are from transcriptions of interviews conducted with parents of seven incessantly crying infants. Three families were presently living the experience and in four families the children ranged from five to 22 years. Four of the fathers were involved in the interviews.

The parents interviewed are all well educated, middle- to upper middle-class Canadians with many resources, yet the impact on their lives has been extraordinary. What is the experience for young, adolescent parents, for those with limited education and resources, and for single mothers?

\section{References}

Bollnow, O.F. (1961). Lived-space. Philosophy Today, 5, 31-38.

Boukydis, C.F.A. (1979). Adult response to infant cries. Unpublished doctoral dissertation. Pennsylvania State University.

Brazelton, T.B. (1962). Crying in infancy. Pediatrics, 29, 579-588.

Brazelton, T.B., \& Cramer, B.G. (1990). The earliest relationship. Reading, MA: Addison-Wesley.

Buytendijk, F.J.J. (1988). The first smile of the child (M. van Manen, Trans.). Phenomenology + Pedagogy, 1, 15-24. (Original work published in 1947)

Oxford Dictionary. (1971). Springfield, MA: G \& C Mirriam.

Rheingold, H.L. (1969). The social and socializing infant. In D.A. Goode (Ed.), Handbook of socialization theory and research (pp. 779-789). New York: Rand McNally.

Thoman, E.B., \& Browder, S. (1987). Born dancing. New York: Harper \& Row. Van den Berg, J.H. (1983). The changing nature of man. New York: Norton.

Wolff, P. (1969). The natural history of crying and other vocalizations in infants. In

B.M. Foss (Ed.), The competent infant: Research and commentary (pp. 257-272). New York: Basic Books. 